\title{
Lifestyle predicts falls independent of physical risk factors
}

\author{
K. A. Faulkner • J. A. Cauley • S. A. Studenski • \\ D. P. Landsittel • S. R. Cummings • K. E. Ensrud • \\ M. G. Donaldson • M. C. Nevitt • \\ for the Study of Osteoporotic Fractures Research Group
}

Received: 5 December 2008 / Accepted: 17 February 2009/Published online: 25 March 2009

(C) The Author(s) 2009. This article is published with open access at Springerlink.com

\begin{abstract}
Summary Many falls occur among older adults with no traditional risk factors. We examined potential independent effects of lifestyle on fall risk. Not smoking and going outdoors frequently or infrequently were independently associated with more falls, indicating lifestyle-related behavioral and environmental risk factors are important causes of falls in older women. Introduction Physical and lifestyle risk factors for falls and population attributable risks (PAR) were examined.

Methods We conducted a 4-year prospective study of 8,378 community-dwelling women (mean age $=71$ years, $\mathrm{SD}=3$ ) enrolled in the Study of Osteoporotic Fractures. Data on number of falls were self-reported every 4 months. Fall
\end{abstract}

This paper was presented in part at the 2007 American Society of Bone and Mineral Research in Honolulu, Hawaii.

\section{K. A. Faulkner $(\bowtie) \cdot$ J. A. Cauley \\ University of Pittsburgh, \\ 130 DeSoto Street, \\ Pittsburgh, PA 15261, USA \\ e-mail: kaf24@pitt.edu}

\section{S. A. Studenski}

University of Pittsburgh,

Pittsburgh, PA 15261, USA

D. P. Landsittel

Duquesne University,

Pittsburgh, PA 15282, USA

S. R. Cummings $\cdot$ M. C. Nevitt

University of California San Francisco,

San Francisco, CA 94107, USA

K. E. Ensrud

Veterans Affairs Medical Center and University of Minnesota,

Minneapolis, MN 55417, USA

\section{G. Donaldson}

San Francisco Coordinating Center,

California Pacific Medical Center Research Institute,

San Francisco, CA 94107, USA rates were calculated (\# falls/woman-years). Poisson regression was used to estimate relative risks (RR).

Results Physical risk factors ( $p \leq 0.05$ for all) included tall height $(R R=0.89$ per 5 in.), dizziness $(R R=1.16)$, fear of falling $(R R=1.20)$, self-reported health decline $(R R=1.19)$, difficulty with Instrumental Activities of Daily Living (IADLs) $(\mathrm{RR}=1.12$, per item), fast usual-paced walking speed $(\mathrm{RR}=$ 1.18 , per $2 \mathrm{SD})$, and use of antidepressants $(\mathrm{RR}=1.20)$, benzodiazepines $(\mathrm{RR}=1.11)$, or anticonvulsants $(\mathrm{RR}=1.62)$. Protective physical factors ( $p \leq 0.05$ for all) included good visual acuity $(R R=0.87$, per $2 \mathrm{SD})$ and good balance $(R R=$ 0.85 vs. poor). Lifestyle predicted fewer falls including current smoking $(\mathrm{RR}=0.76)$, going outdoors at least twice weekly but not more than once a day $(\mathrm{RR}=0.89$ and vs. twice daily). High physical activity was associated with more falls but only among IADL impaired women. Five potentially modifiable physical risk factors had $\mathrm{PAR} \geq 5 \%$.

Conclusions Fall interventions addressing modifiable physical risk factors with $\mathrm{PAR} \geq 5 \%$ while considering environmental/ behavioral risk factors are indicated.

Keywords Behavioral risk factors · Fall rates · Falls · Lifestyle $\cdot$ Physical risk factors $\cdot$ Risk factors

\section{Introduction}

Thirty percent of women aged 65 years and older fall at least once annually and $11 \%$ fall at least twice, averaging a total of 497 falls per 1,000 women each year [1]. Thirty-one percent of falls in older adults result in injuries leading to a doctor's visit or restriction in activities for at least 1 day [2]. There were 15,802 deaths from a fall in 2005 [3], and rates of fall-related injury hospitalizations [4] and deaths [5] are increasing.

Falls in older adults are caused by physical and nonphysical factors that contribute to postural instability or an inability to recover balance, such as after a slip or a 
trip. While some falls may result from a single cause, such as a sudden loss of consciousness or slipping on ice, most are multifactorial. Previously identified physical risk factors include chronic and acute health conditions and medications and their side effects [1, 6-10]. Presence of environmental hazards (e.g., dark stairways and obstacles) and risk-taking (e.g., climbing on step stools and rushing) [10-12] are implicated in many falls among older adults; however, their role independent of physical factors is uncertain.

The Study of Osteoporotic Fractures (SOF) is the largest and most comprehensive study of risk factors for falls in older Caucasian community-dwelling women. Limitations of prior prospective cohort studies $[1,6,7,9,10]$ include small or unrepresentative samples, assessing a limited scope of risk factors, and not examining interactions among risk factors. Prior studies have focused on risk factors for becoming a faller $[6,7,9,10]$, whereas we have focused on cumulative falls to address the total burden of falls since fall-related injury and mortality risk increases with each additional fall $[13,14]$. Our objectives in this study include identifying independent risk factors for more falls in older women with consideration of behavioral and environmental factors independent of physical risk factors and calculating population attributable risk.

\section{Methods}

Sample and design

Nine thousand seven hundred four community-dwelling women aged 65 years and older were enrolled in the Study of Osteoporotic Fractures in 1986-1988. SOF participants were recruited from population-based lists in Baltimore, MD; Portland, OR; Minneapolis, MN; and the Monongahela Valley near Pittsburgh, PA. Eligible participants for SOF included Caucasians, women able to walk without assistance of another person, and women without hip replacements bilaterally. The analysis sample consisted of 8,378 women ( $86.3 \%$ of women) who provided complete data on age, history of falls at baseline, and incident falls over 4 years. All women provided written informed consent and participated in extensive clinical examination and interviews upon enrollment.

\section{Incident falls}

Women were contacted about falls by postcards and telephone calls every 4 months beginning at baseline and continuing over 4 years. These queries included whether or not they had fallen during the past 4 months and (if so) how many times. The definition of falls was reinforced at every SOF examination as "landing on the floor or ground, or falling and hitting an object like a table or a chair" [15]. Incident fall rates were calculated by dividing the number of falls by woman-years (including recurring falls and corresponding woman-years).

Potential risk factors and confounders

Potential risk factors and confounders were classified into five categories: demographics and anthropometrics, geriatric conditions, medications, physical function, and lifestyle. All risk factors were considered to be physical factors except for lifestyle which were considered to be behavioral and environmental factors.

Demographics and anthropometrics Age and education were self-reported. The highest grade or year of school completed was recorded, with completed high school defined as 12 or more years. Waist and hip circumferences, body height in centimeters and weight in kilograms (by stadiometer) were measured and body mass index (BMI) calculated $\left(\mathrm{kg} / \mathrm{cm}^{2}\right)$.

Geriatric conditions A history of one or more falls in the year prior to study enrollment, physician diagnoses (stroke, Parkinson's disease, diabetes, and arthritis), dizziness upon standing, fear of falling, and health compared to others of own age (excellent, good, fair, poor, or very poor) and also compared to 12 months ago (better, same, worse) were selfreported. Corrected visual acuity [16], contrast sensitivity [17], and depth perception [18] were measured. Orthostatic hypotension was defined as a drop in systolic blood pressure of $20 \mathrm{~mm} \mathrm{Hg}$ or more upon standing from a supine position after $1 \mathrm{~min}$ or if the standing systolic blood pressure is 90 or less. Cognitive function was assessed using the short Mini Mental State Examination [19] and impairment scored as $<23$ of 26 possible.

Medications Participants were also asked to bring all of their prescription and nonprescription medications and supplement pills to the clinic. Use of central nervous system (CNS)-active medications at baseline (1986-1988) was obtained by self-report by asking questions focused on indication for use; verification of use was accomplished by inspection of medication containers. Current use of antidepressants, antihistamines, barbiturates, benzodiazepines, muscle relaxants, and nonbenzodiazepine sedative hypnotics were assessed using two questions "taken any medications in the past 12 months for anxiety or nerves or to relax muscles" and "taken any medications in the past 12 months to help you sleep." Any use of antiepileptics was assessed using two questions "ever taken medications for seizures" and "what is the name of the drug you used the longest." All medications taken for seizures (if current use), 
anxiety or nerves or to relax and help with sleep were reviewed and categorized by medication class.

Physical function Self-reported difficulty (yes/no) on five Instrumental Activities of Daily Living (IADLs) were recorded: walking two to three blocks, climbing up ten steps, preparing meals, doing heavy household chores, and shopping [20]. Isometric hand-grip strength at $90^{\circ}$ (Preston Grip Dynamometer; Takei Kiki Kogyo, Tokyo, Japan) was measured using the average of the right and left hands. Standing balance was assessed using a series of three tandem stands (side by side and semi- and full tandem). Each stance was held up to $10 \mathrm{~s}$ with eyes open and closed. Women were scored as poor if unable to hold the side by side or semi-tandem, fair if unable to hold the full tandem, and good if able to hold the full tandem. Time to perform five chair stands without using arms was recorded. Walking speed was measured over $6 \mathrm{~m}$ at a usual pace. Timed toe-tapping involved ten repetitions between alternating 7.5 -cm-diameter circles on the floor spaced $30 \mathrm{~cm}$ apart. The number of stepups completed while grasping a handrail in $10 \mathrm{~s}$ was obtained on a $23-\mathrm{cm}$-high step.

Lifestyle Women were queried about smoking and alcohol. Smoking status (e.g., never, past, or current) was determined using response to "have you smoked at least one hundred cigarettes in your entire life?" and "do you smoke now?" Alcohol consumption was assessed as the number of drinks per week in the past 30 days. To estimate mobility outside the home [21], women were asked "How frequently do you go outdoors in good weather?" Physical activity was assessed using a modified version of the Harvard Alumni Questionnaire [22], which asks about the frequency and duration of recreational physical activity, blocks walked, and stair climbing in the past year. A summary estimate of total energy expenditure was calculated [22]. Participants were also asked, "About how many hours per week do you usually spend doing heavy household chores, such as scrubbing floors, vacuuming, sweeping, yard work, gardening, or shoveling snow?" To estimate inactivity, women were asked how many hours per day they spend lying and sitting.

\section{Statistical analyses}

All analyses were performed using STATA 9.2 (StataCorp, College Station, TX). Relative risks were calculated from Poisson regression models using generalized estimating equations (GEE). GEE correctly adjusts standard errors for within-subject correlations [23]. Data on the number of falls per 4-month follow-up period were truncated at 16 to stabilize parameter estimates from any extreme influential values. We used a model-building strategy. All factors were initially prescreened in base models adjusted for age, fall history, and clinic with a $p \leq 0.05$ denoting statistical significance. All continuous variables were further categorized into quartiles to consider alternative threshold or curvilinear relationships with falls, which when observed were used in subsequent analyses. All prescreened factors were then rescreened in models additionally adjusted for screened demographic and anthropometric characteristics, plus all other prescreened same-category factors. The final multivariate model included all rescreened variables with a $p \leq 0.15$. Interactions were examined within and across the following risk factor domains: geriatric conditions, physical function, and lifestyle.

Relative risks for continuous variables were expressed per a two standard deviation (SD) unit, (except for height which used a $2.2 \mathrm{SD}=5 \mathrm{in}$.), since a $2 \mathrm{SD}$ scaling ( $1 \mathrm{SD}$ above and below the mean) on continuous variables is directly comparable with dichotomous variables [24]. We also calculated absolute risks for each potential risk factor (e.g., crude incident fall rates) that was independently associated with fall rates and according to the number of risk factors present. For continuous variables, an individual was coded as having a risk factor when the value was greater than $1 \mathrm{SD}$ above the mean or less than $1 \mathrm{SD}$ below the mean (as appropriate). An individual was coded as having the IADL risk factor if they reported difficulty with one or more IADL. Population attributable risk (PAR) was calculated for each risk factor using crude incident fall rates: [(fall rate in the total population-fall rate in those not exposed to the risk factor)/ fall rate in the total population] $\times 100$ [26]. PAR represents the excess fall rate in the population associated with a given risk factor, reflecting the public health burden of recurring falls in older adults. Since a fall is a multifactorial condition, PARs for individual risk factors will not add to $100 \%$.

\section{Results}

The mean age of our sample $(N=8,378)$ was 71 years $(\mathrm{SD}=3)$. Characteristics of the women are shown in Table 1. The distribution of cumulative falls in the sample is presented in Fig. 1. During the 4-year study, women reported 15,416 falls over 33,512 woman-years, with an overall fall rate of 460 falls/1,000 woman-years.

Factors that were associated with fall rates in the final multivariate model $(p \leq .05)$ are shown in Table 2. Geriatric conditions, including fall history and ever use of antiepileptic drugs (AED), were strong risk factors (relative risk (RR) increase or decrease $\geq 50 \%$ ). Fall rates were two times higher among women with a history of falls at baseline compared to women with no prior history of falls and $62 \%$ higher among women who had used AED as compared to women who had never used AED. 
Table 1 Baseline characteristics overall and according to cumulative falls over 4 years

\begin{tabular}{|c|c|c|c|c|c|}
\hline Measure & $\begin{array}{l}\text { All } \\
N=8,378\end{array}$ & $\begin{array}{l}0 \text { falls } \\
N=3,383\end{array}$ & $\begin{array}{l}1 \text { fall } \\
N=1,904\end{array}$ & $\begin{array}{l}2 \text { falls } \\
N=1,208\end{array}$ & $\begin{array}{l}3 \pm \text { falls } \\
N=1,883\end{array}$ \\
\hline \multicolumn{6}{|l|}{ Demographics and anthropometrics } \\
\hline \multicolumn{6}{|l|}{ Age, in years $(\%)$} \\
\hline $65-69$ & 44.2 & 46.9 & 43.9 & 44.4 & 39.3 \\
\hline $70-74$ & 31.4 & 31.7 & 31.5 & 30.5 & 31.2 \\
\hline $75-79$ & 15.4 & 14.6 & 15.4 & 16.0 & 16.6 \\
\hline $80-84$ & 7.2 & 5.4 & 7.5 & 7.6 & 9.8 \\
\hline $85+$ & 1.8 & 1.4 & 1.7 & 1.4 & 3.1 \\
\hline BMI $\left(\mathrm{kg} / \mathrm{m}^{2}\right)$ & $26.4(4.4)$ & $26.4(4.4)$ & $26.4(4.5)$ & $26.3(4.4)$ & $26.5(4.5)$ \\
\hline Height (cm) & $159.3(5.8)$ & $159.5(5.7)$ & $159.5(5.9)$ & $159.2(5.7)$ & $159.0(6.1)$ \\
\hline Ratio of waist-to-hip circumferences & $0.81(0.06)$ & $0.81(0.06)$ & $0.81(0.06)$ & $0.81(0.06)$ & $0.81(0.06)$ \\
\hline \multicolumn{6}{|l|}{ Geriatric conditions } \\
\hline Stroke $(\%)$ & 2.8 & 2.1 & 2.5 & 2.9 & 4.1 \\
\hline Parkinson's (\%) & 0.5 & 0.5 & 0.3 & 0.7 & 0.9 \\
\hline Diabetes $(\%)$ & 6.6 & 5.9 & 6.6 & 6.7 & 7.8 \\
\hline Arthritis (\%) & 63.0 & 58.4 & 63.3 & 63.8 & 70.6 \\
\hline Dizziness upon standing (\%) & 19.2 & 16.6 & 19.4 & 19.4 & 23.5 \\
\hline Fear of falling $(\%)$ & 45.4 & 45.4 & 39.3 & 44.3 & 48.6 \\
\hline Visual acuity, number correct & $49.4(7.1)$ & $49.8(6.6)$ & $49.4(7.0)$ & $49.3(7.4)$ & $48.6(7.9)$ \\
\hline Depth perception, SD of 4 scores & $2.21(2.6)$ & $2.21(2.5)$ & $2.18(2.6)$ & $2.21(2.5)$ & $2.43(2.9)$ \\
\hline Contrast sensitivity, mean number correct & $74.6(35.5)$ & $75.2(34.6)$ & $75.0(35.0)$ & $74.2(36.3)$ & $73.2(37.2)$ \\
\hline Health is fair/poor $(\%)$ & 15.8 & 13.7 & 15.4 & 17.1 & 19.0 \\
\hline Health worsened vs. 12 months ago (\%) & 11.0 & 8.3 & 10.4 & 11.7 & 16.1 \\
\hline Fall history $(\%)$ & 29.4 & 18.6 & 26.8 & 34.4 & 48.1 \\
\hline \multicolumn{6}{|l|}{ CNS-active medications (\%) } \\
\hline Benzodiazepines & 15.3 & 13.9 & 14.2 & 16.4 & 18.2 \\
\hline Antidepressants & 3.3 & 2.5 & 2.8 & 4.3 & 4.8 \\
\hline Antiepileptics & 1.7 & 1.1 & 1.0 & 2.3 & 3.0 \\
\hline \multicolumn{6}{|l|}{ Physical function } \\
\hline Number of IADLs with difficulty, range $0-5$ & $0.59(1.04)$ & $0.47(0.92)$ & $0.57(1.01)$ & $0.60(1.06)$ & $0.83(1.21)$ \\
\hline \multicolumn{6}{|l|}{ Tandem stand balance, eyes open (\%) } \\
\hline Poor & 6.8 & 5.8 & 5.8 & 6.2 & 9.8 \\
\hline Fair & 27.0 & 24.9 & 27.7 & 26.4 & 30.3 \\
\hline Good & 66.3 & 69.3 & 66.5 & 67.3 & 59.9 \\
\hline \multicolumn{6}{|l|}{ Tandem stand balance, eyes closed (\%) } \\
\hline Poor & 31.8 & 28.3 & 32.5 & 32.9 & 36.8 \\
\hline Fair & 52.8 & 54.8 & 52.2 & 52.0 & 50.3 \\
\hline Good & 15.4 & 16.9 & 15.3 & 15.1 & 12.9 \\
\hline Walking speed $(\mathrm{m} / \mathrm{s})$ & $1.02(.21)$ & $1.03(.20)$ & $1.03(.20)$ & $1.02(.22)$ & $1.00(.24)$ \\
\hline Chair-stand time (s) & $12.3(4.4)$ & $11.9(3.9)$ & $12.0(3.9)$ & $12.4(4.1)$ & $13.1(5.5)$ \\
\hline Rapid stepping, number completed in $10 \mathrm{~s}$ & $9.6(2.6)$ & $9.7(2.4)$ & $9.6(2.6)$ & $9.6(2.7)$ & $9.3(2.8)$ \\
\hline Grip strength $(\mathrm{kg})$ & $22.4(4.3)$ & $22.8(4.3)$ & $22.4(4.2)$ & $22.1(4.4)$ & $21.8(4.5)$ \\
\hline Toe taps, seconds to complete 10 & $5.0(1.9)$ & $4.9(1.7)$ & $5.0(1.9)$ & $5.1(1.8)$ & $5.3(2.4)$ \\
\hline \multicolumn{6}{|l|}{ Lifestyle } \\
\hline \multicolumn{6}{|l|}{ Number of alcoholic drinks per week, $\%$} \\
\hline None & 45.5 & 45.7 & 44.2 & 42.6 & 48.1 \\
\hline One or less weekly & 41.4 & 41.6 & 42.9 & 43.3 & 38.3 \\
\hline More than one weekly & 13.1 & 12.7 & 12.9 & 14.1 & 13.6 \\
\hline
\end{tabular}


Table 1 (continued)

\begin{tabular}{|c|c|c|c|c|c|}
\hline Measure & $\begin{array}{l}\text { All } \\
N=8,378\end{array}$ & $\begin{array}{l}0 \text { falls } \\
N=3,383\end{array}$ & $\begin{array}{l}1 \text { fall } \\
N=1,904\end{array}$ & $\begin{array}{l}2 \text { falls } \\
N=1,208\end{array}$ & $\begin{array}{l}3 \pm \text { falls } \\
N=1,883\end{array}$ \\
\hline \multicolumn{6}{|l|}{ Smoking (\%) } \\
\hline Never & 60.5 & 59.6 & 60.2 & 61.6 & 61.9 \\
\hline Past & 29.8 & 28.6 & 30.1 & 30.2 & 31.4 \\
\hline Current & 9.6 & 11.8 & 9.7 & 8.2 & 6.6 \\
\hline \multicolumn{6}{|l|}{ Frequency goes outdoors $(\%)$} \\
\hline $2+/$ day & 64.6 & 65.6 & 63.6 & 62.7 & 65.1 \\
\hline$\geq 2 /$ week but $\leq 1 /$ day & 34.2 & 33.5 & 35.5 & 35.8 & 33.1 \\
\hline$\leq 1 /$ week & 1.2 & 0.9 & 0.9 & 1.5 & 1.7 \\
\hline \multicolumn{6}{|l|}{ Frequency leaves the neighborhood (\%) } \\
\hline $2+/$ day & 14.1 & 14.2 & 13.4 & 12.5 & 15.8 \\
\hline$\geq 2 /$ week but $\leq 1 /$ day & 76.7 & 77.0 & 77.6 & 78.1 & 74.5 \\
\hline$\leq 1 /$ week & 9.1 & 8.8 & 8.9 & 9.3 & 9.8 \\
\hline On-feet $\leq 4$ hours/day, $\%$ & 9.2 & 8.5 & 9.4 & 8.2 & 10.8 \\
\hline Physical activity in past year, in (kcal) & $1,614(1,646)$ & $1,598(1,598)$ & $1,577(1,560)$ & $1,633(1,708)$ & $1,668(1,770)$ \\
\hline Hours/week does household chores & $8.6(9.3)$ & $9.0(9.5)$ & $8.4(9.0)$ & $8.7(9.6)$ & $7.8(8.8)$ \\
\hline
\end{tabular}

Values are mean $(\mathrm{SD})$ or percent

Other risk factors suggested relatively moderate $(25 \leq \mathrm{RR}$ increase or decrease $<50 \%$ ) to weak effects (RR increase or decrease $<25 \%$ ). High levels of physical activity involving the third and fourth quartiles were associated with higher fall rates of $12 \%$ and $26 \%$, respectively, compared to women in the first quartile. Current smoking was associated with $24 \%$ fewer falls as compared to never smoking. Being afraid of falling, reporting worsened general health in the year prior to baseline, and using antidepressants were all associated with $19-20 \%$ more falls than women without each respective condition. A 2 SD increase in usual-paced walking speed was associated with $18 \%$ more falls.

Women who reported feeling dizzy upon standing up from a chair had $16 \%$ more falls compared to women who did not. A one-item increase in the number of IADLs with difficulty was associated with $12 \%$ more falls. Current use of benzodiazepines was associated with an $11 \%$ higher rate of falls. Protective factors identified included tall body height ( $11 \%$, per 2.2 SD change), good visual acuity ( $13 \%$, per 2 SD change), going outdoors at least twice weekly but not more than once a day ( $11 \%$ as compared to twice daily), and good balance ( $15 \%$ as compared to poor).

Factors included in the final multivariate (MV) model that were not significant are shown in Table 3. Factors not associated with fall rates in base models (data not shown) included having a high school education, orthostatic hypotension, cognitive impairment, and use of antihistamines, barbituates, nonbenzodiazepine sedative hypnotics, and muscle relaxant drugs $(p>0.05$ for all).

\section{Risk factor interactions}

One interaction was identified among potential risk factors $(p \leq 0.05)$ : IADL impairment and physical activity $(p<0.01)$. Among the 5,621 women reporting with no IADL impairment (67.1\% of women), high median levels of physical activity was not independently associated with more falls $(\mathrm{RR}=1.06$; 95\% CI, 0.97-1.16), whereas among all remaining women
Fig. 1 Distribution of cumulative falls in the sample

\section{Four-year cumulative falls, $\mathrm{N}=8,378$}

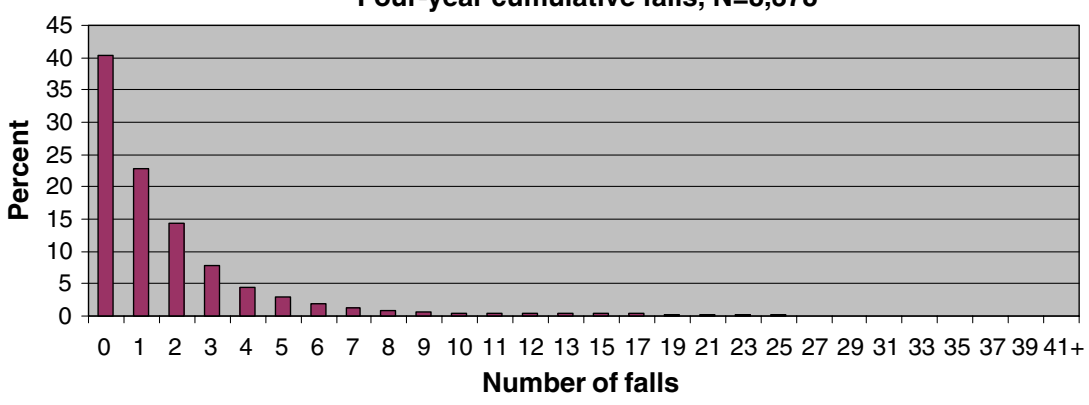


Table 2 Factors associated with fall rates in multivariate-adjusted models, $N=8,378$

\begin{tabular}{|c|c|c|}
\hline & \multicolumn{2}{|c|}{ Relative risk $(95 \% \text { confidence interval })^{\mathrm{a}}$} \\
\hline & Base model $^{\mathrm{b}}$ & Full model ${ }^{\mathrm{c}}$ \\
\hline \multicolumn{3}{|l|}{ Demographics and anthropometrics } \\
\hline Taller height, per 5 in. & $0.95(0.92,0.98)$ & $0.89(0.82,0.96)$ \\
\hline \multicolumn{3}{|l|}{ Geriatric conditions } \\
\hline Dizziness upon standing & $1.29(1.18,1.41)$ & $1.16(1.06,1.27)$ \\
\hline Fear of falling & $1.37(1.27,1.47)$ & $1.20(1.11,1.29)$ \\
\hline Visual acuity, unit $=2 \mathrm{SD}$ & $0.83(0.77,0.90)$ & $0.87(0.81,0.94)$ \\
\hline Self-rated health decline & $1.48(1.31,1.66)$ & $1.19(1.04,1.35)$ \\
\hline Fall history at baseline & $2.28(2.12,2.46)$ & $2.05(1.91-2.21)$ \\
\hline \multicolumn{3}{|l|}{ CNS-active medications } \\
\hline Use of benzodiazepines & $1.27(1.14,1.40)$ & $1.11(1.01,1.23)$ \\
\hline Use of antidepressants & $1.45(1.20,1.75)$ & $1.20(1.00,1.45)$ \\
\hline Use of antiepileptics & $1.77(1.41,2.22)$ & $1.62(1.31,2.02)$ \\
\hline \multicolumn{3}{|l|}{ Physical function } \\
\hline Number of IADL with difficulty, unit=1 & $1.21(1.17,1.25)$ & $1.12(1.07,1.17)$ \\
\hline \multicolumn{3}{|l|}{ Standing balance, eyes closed (vs. poor) } \\
\hline Fair & $0.82(0.76,0.89)$ & $0.95(0.88,1.04)$ \\
\hline Good & $0.73(0.65,0.81)$ & $0.85(0.76,0.95)$ \\
\hline Faster usual walking speed, unit $=2 \mathrm{SD}$ & $0.84(0.77,0.91)$ & $1.18(1.08-1.30)$ \\
\hline \multicolumn{3}{|l|}{ Lifestyle } \\
\hline \multicolumn{3}{|l|}{ Smoking status (vs. never) } \\
\hline Past & $1.04(0.96,1.13)$ & $1.06(0.98,1.15)$ \\
\hline Current & $0.82(0.71,0.95)$ & $0.76(0.66,0.88)$ \\
\hline \multicolumn{3}{|l|}{ Physical activity (kcal; vs. Qrtl 1) } \\
\hline Qrtl 2 & $0.85(0.77,0.95)$ & $1.03(0.92,1.14)$ \\
\hline Qrtl 3 & $0.86(0.78,0.96)$ & $1.12(1.01,1.25)$ \\
\hline Qrtl 4 & $0.94(0.84,1.06)$ & $1.26(1.10,1.44)$ \\
\hline \multicolumn{3}{|l|}{ Frequency goes outdoors (vs. 2+/day) } \\
\hline$\geq 2 /$ week but $\leq 1 /$ day & $0.97(0.89,1.05)$ & $0.89(0.81,0.96)$ \\
\hline$\leq 1 /$ week & $1.78(1.20,2.62)$ & $1.02(0.66,1.59)$ \\
\hline
\end{tabular}

${ }^{a}$ Relative risk represents a ratio of incident fall rates obtained from the Poisson regression model. The RR corresponds to relative increase or decrease in fall rates associated with a given level or unit change in a given factor

${ }^{\mathrm{b}}$ Model-adjusted for age, fall history at baseline, and clinic

${ }^{\mathrm{c}}$ Full model includes all of the factors listed in the above table and age, clinic, waist-to-hip circumference, stroke, Parkinson's disease, diabetes, arthritis, self-rated health, standing balance with eyes open, rapid stepping, grip strength, alcohol consumption, hours per day spent on feet, and hours per week does household chores

with one or more IADL impairment, high median level of physical activity was independently associated with more falls $(\mathrm{RR}=1.31 ; 95 \% \mathrm{CI}, 1.14-1.52)$.

\section{Absolute fall risk}

The absolute risk of falling is shown by number of risk factors overall and stratified on age (Fig. 2). Absolute fall risks were slightly higher among women aged 75 years and older compared to women aged 65 to 74 years in any given category of number of risk factors except for nine to 12 risk factors. The absolute fall risk increased substantially with the number of risk factors among younger women, older women, and overall, $p$ (trend) $<0.001$ for all.

Population attributable risk

PAR for all potential risk factors are shown in Fig. 3. Most falls in the population were attributable to fall history (28\%) and not currently smoking (24\%), as well as five potentially modifiable risk factors: fair or poor balance (21\%), fear of falling (19\%), IADLs impairment (16\%), 
Table 3 Factors not

independently associated with fall rates in multivariate models, $N=8,378$
Relative risk ( $95 \%$ confidence interval $)^{\mathrm{a}}$

Base model ${ }^{\mathrm{b}}$

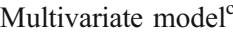

\begin{tabular}{|c|c|c|}
\hline & \multicolumn{2}{|c|}{ Relative risk $(95 \% \text { confidence interval })^{\mathrm{a}}$} \\
\hline & Base $_{\text {model }}{ }^{\mathrm{b}}$ & Multivariate $\operatorname{model}^{\mathrm{c}}$ \\
\hline \multicolumn{3}{|l|}{ Demographics and anthropometrics } \\
\hline \multicolumn{3}{|l|}{ Age, in years (vs. 65-69) } \\
\hline $70-74$ & $1.03(0.96,1.10)$ & $0.94(0.87,1.01)$ \\
\hline $75-79$ & $1.11(1.02,1.21)$ & $0.98(0.89,1.07)$ \\
\hline $80-84$ & $1.25(1.11,1.40)$ & $1.00(0.87,1.14)$ \\
\hline $85+$ & $1.38(1.18,1.60)$ & $1.04(0.88,1.24)$ \\
\hline Waist-to-hip circumference, unit $=2 \mathrm{SD}$ & $1.11(1.03,1.19)$ & $1.03(0.96,1.11)$ \\
\hline \multicolumn{3}{|l|}{ Geriatric conditions } \\
\hline Stroke & $1.48(1.23,1.79)$ & $1.13(0.93,1.38)$ \\
\hline Parkinson's & $1.77(1.20,2.62)$ & $1.51(0.95,1.38)$ \\
\hline Diabetes & $1.36(1.15,1.62)$ & $1.15(0.96,1.37)$ \\
\hline Arthritis & $1.23(1.14,1.33)$ & $1.07(0.99,1.17)$ \\
\hline Health self-rated as fair or poor & $1.20(1.13,1.26)$ & $1.05(0.93,1.19)$ \\
\hline \multicolumn{3}{|l|}{ Physical function } \\
\hline \multicolumn{3}{|l|}{ Standing balance, eyes open (vs. poor) } \\
\hline Fair & $0.75(0.64,0.88)$ & $0.89(0.76,1.04)$ \\
\hline Good & $0.63(0.54,0.88)$ & $0.83(0.71,0.98)$ \\
\hline Rapid stepping, unit $=2 \mathrm{SD}$ & $0.76(0.70,0.82)$ & $0.93(0.84,1.03)$ \\
\hline Grip strength, unit $=2 \mathrm{SD}$ & $0.81(0.74,0.63)$ & $0.94(0.87,1.03)$ \\
\hline \multicolumn{3}{|l|}{ Lifestyle } \\
\hline \multicolumn{3}{|l|}{ Number of alcoholic drinks (vs. 0) } \\
\hline One or less weekly & $0.85(0.79,0.93)$ & $0.94(0.86,1.02)$ \\
\hline More than one weekly & $0.86(0.76,0.96)$ & $0.94(0.84,1.05)$ \\
\hline On-feet $\leq 4 \mathrm{~h} /$ day & $1.14(1.00,1.30)$ & $0.99(0.88,1.12)$ \\
\hline \multicolumn{3}{|l|}{ Hours/week does household chores (vs. 3-5) } \\
\hline $0-2$ & $1.16(1.05,1.28)$ & $1.07(0.97,1.18)$ \\
\hline $6-10$ & $1.01(0.91,1.11)$ & $1.00(0.90,1.11)$ \\
\hline $11-64$ & $1.00(0.90-1.11)$ & $1.02(0.90-1.12)$ \\
\hline
\end{tabular}

${ }^{a}$ Relative risk represents a ratio of incident fall rates obtained from the Poisson regression model. The RR corresponds to relative increase or decrease in fall rates associated with a given level or unit change in a given factor

${ }^{\mathrm{b}}$ Model-adjusted for age, fall history at baseline, and clinic

${ }^{\mathrm{c}}$ Full model includes all of the factors listed in the above table and clinic, height, dizziness, fear of falling, visual acuity, self-rated health decline, fall history at baseline, use of benzodiazepines, use of antidepressants, use of antiepileptics, number of IADL with difficulty, standing balance with eyes closed, usual walking speed, smoking status, physical activity, and frequency goes outdoors dizziness upon standing (7\%), and poor visual acuity (7\%). Fewest falls were attributable to faster walking speed $(0.01 \%)$, high physical activity $(0.7 \%)$, going outdoors frequently or infrequently (1.1\%), use of AED (1.7\%), and use of antidepressants $(2.0 \%)$.

\section{Discussion}

In this 4-year prospective study of 8,378 communitydwelling older women, we identified independent associations of physical and lifestyle factors on fall rates. Lifestyle factors are possible markers of exposure to environmental hazards and engagement in riskier activities. For example, a relationship of more falls and high physical activity (involving recreational activity, blocks walked, and stair climbing) was dependent on the presence of IADL impairment, potentially indicating risk-taking. Five potentially modifiable physical risk factors, including poor standing balance, fear of falling, IADL impairment, dizziness upon standing, and poor visual acuity, each contributed to at least $5 \%$ of falls among older community-dwelling women and fall history to $28 \%$.

The physical risk factors identified are consistent with those reported in prior observational studies: poor visual acuity [25], IADL impairment [26, 27], poor standing balance [26], fear of falling [27], use of AED, antidepressants, and benzodiazepines [8, 10, 28], dizziness upon standing [1, 27], self-rated health, and fall history [9, 27, 29]. In the laboratory, fear of falling is associated with poor balance [30] and ineffective recovery strategies during an unexpected perturbation [31]. Fear of falling may also lead to reduced social contacts [32]. Reduced social contacts with family members is associated with more falls [33], possibly due to a lack of educational and physical resources that reduce participation in riskier activities and/or increase home safety environmental modifications. Thus, fear of falling may have physical as well as behavioral and 


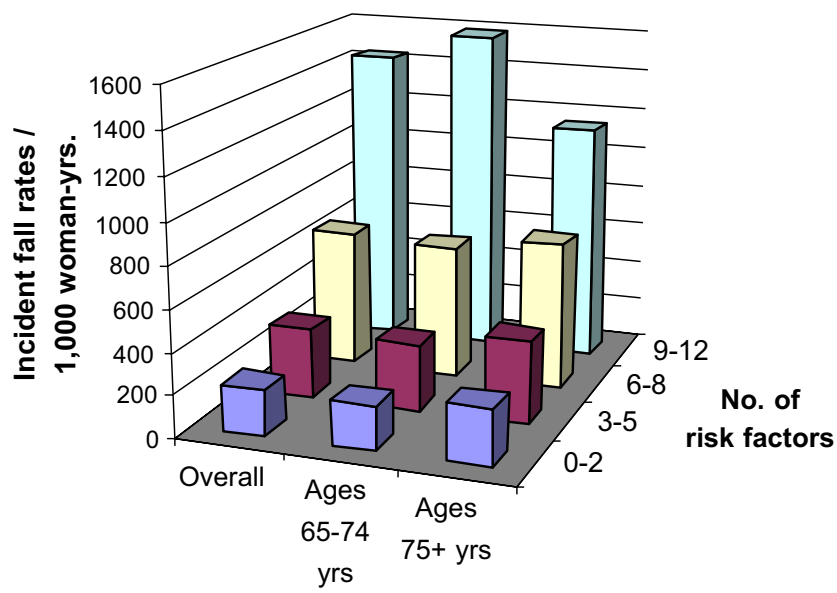

Fig. 2 Absolute fall risk according to number of risk factors. Potential risk factors included short body height, dizziness upon standing, fear of falling, health decline in the past year, fall history, poor vision, current use of benzodiazepines, current use of antidepressants, any use of antiepileptics, past or never smoking, high physical activity, going outdoors frequently or infrequently, IADL impairment, fair or poor standing balance, and fast walking speed

environmental components. Since falls are multifactorial, fall history is probably a marker for having multiple risk factors.

Usual-walking speed and body height were considered as physical factors; however, their independent associations with falls after adjusting with physical function suggests they may have a behavioral and/or environmental component. An association of faster usual-walking pace and more falls is consistent with laboratory studies indicating that compared to slow walking, fast walking is associated with a higher likelihood of a fall in the event of a trip [34] due to increased anterior body rotation following a trip. Shorter body height was associated with more falls. Shorter legs may result in having less favorable stepping trajectories needed for clearing a given size obstacle. A shorter reach, in a maladapted setting, may contribute to risk-taking out of necessity, such as standing on stools or chairs and reaching beyond one's center of mass in order to maintain independence in the community.
Going outdoors and short stature may be markers of increased exposure to environmental hazards and/or more risk-taking. Going outdoors more often in good weather was associated with more falls, possibly marking where most falls occur [35]. Consistent with prior studies [7], current smokers fell less often than women who have never smoked. While current smokers included in the study may represent a selective sample of healthy smokers who are resilient to smoking-related disease, current smoking may also be a marker for being better able to cope with smoking-related diseases, e.g., elimination of destabilizing activities while remaining active. Current smokers scored similarly on measures of physical performance as nonsmokers but reported less physical activity even among unimpaired women.

High levels of physical activity, involving recreational activities, stair climbing, and blocks walked, were associated with more falls among IADL-impaired women, consistent with prior studies $[1,29]$. Women who are IADL impaired and also walk and use stairs often may do so out of necessity to maintain their independence in the community (e.g., risktaking) and therefore increase their exposure to environmental hazards. Even a slight displacement of an individual's center of gravity outside of its base of support may jeopardize postural stability among IADL-impaired women. Poor physically functioning older adults were as likely (or more) to have environmental hazards present in their homes compared to better-functioning older adults [36, 37].

Poor standing balance, fear of falling, IADL impairment, poor visual acuity, and postural dizziness are all potentially modifiable risk factors which each contribute to $5 \%$ or more of all falls, therefore warranting focus from clinical and community-wide fall intervention programs. Randomized controlled trials have been successful in preventing falls by reducing fear of falling [38], improving standing balance [39], reducing IADL impairment [40], and withdrawing medications [41]. However, a recent randomized controlled trial of frail older adults reported that improved vision increased falls [42]. A possible explanation is that lifestyle changes may accompany improved vision, thus increasing exposure to environmental hazards and/or risk-
Fig. 3 Population attributable risk in older communitydwelling women
Population Attributable Risk \%

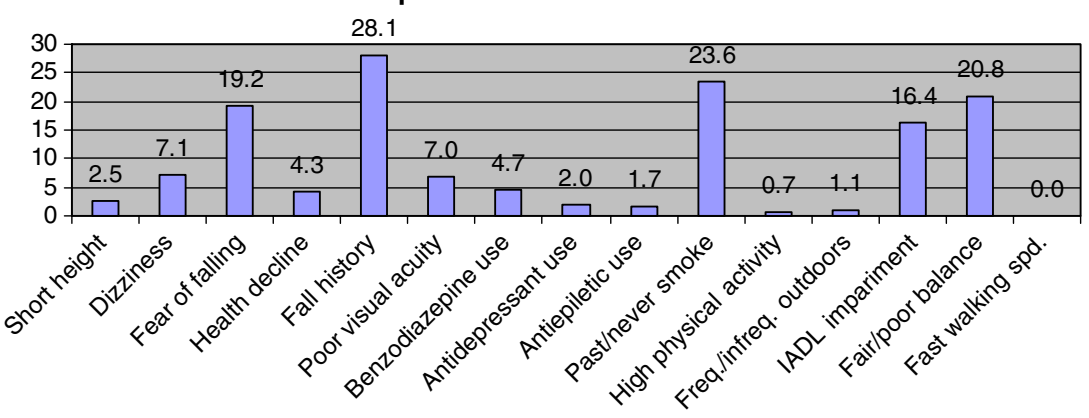


taking, which may be particularly problematic in frail elderly [11]. While use of AED is a strong risk factor, it contributes to less than $5 \%$ of falls suggesting it would be best addressed by healthcare professionals in individual patients. A history of falls contributed to more falls in the population $(28 \%)$ than any other risk factor; therefore, preventing falls even among those who have not yet fallen is a worthy public health goal.

We identified 15 independent potential risk factors, and not surprisingly, those with the most risk factors had the highest absolute risk. Visually, absolute fall risk was lower among women aged 75 years and older compared to women aged 65 to 74 years in every number of risk factor category except 912. While very few women had nine to 12 risk factors $(1.4 \%$ and $2.0 \%$ of women aged $65-74$ and $\geq 75$ years, respectively), selection bias among women aged 75 years and older who have nine to 12 risk factors may explain why their fall rates appear low relative to women aged 65-74 years.

Many risk factors are modifiable, and each risk factor modified may reduce falls, with the greatest impact among women having many risk factors. Our results are therefore somewhat consistent with fall prevention guidelines [43] recommending multifactorial risk assessment and targeted interventions; however, these guidelines have focused on the frail faller. Due to the independent relationships of lifestyle factors and fall risk identified in our study, we think there are actually two populations of fallers: frail and vigorous. Thus, in the context of a recent systematic review and meta analysis indicating the evidence is weak that multifactorial risk assessment and targeted interventions prevent falls [44], we believe fall prevention guidelines should be expanded to include nontraditional risk factors associated with not smoking, going outdoors frequently, walking at a fast usual-paced walking speed, and high physical activity.

Our study has important strengths. Our study is the largest and most comprehensive assessment of risk factors for falls. Our sample included over 8,300 women aged 6589 years with a wide variation in physical function and lifestyles from four large metropolitan areas in the USA. Prior prospective studies in unselected samples of communitydwelling adults have been small including sample sizes between 306 and 761 and not nearly as comprehensive as our current study $[1,6,10,11]$. Risk factors identified in less comprehensive studies are less able to rule out confounding effects due to unmeasured risk factors. Although one study included nearly 3,000 older adults, it did not assess physical performance [7]. Furthermore, our study profoundly improves on prior studies by calculating population attributable risks and addressing a critical need to reduce the burden of recurring falls [15] and not just the risk for becoming a faller.

While our study has major strengths, there are some limitations. First, our findings were based on a cohort of older Caucasian women and may not apply to other populations. Findings should generalize to more to healthier Caucasian women since participation was voluntary and remaining active over the study follow-up period was required to be included in the analysis. Use of CNS-active medications included ever use (AED) and any use in the past 12 months (all other CNS-active medications). Because we did not specify the degree of current use more precisely, we may have underestimated associations of CNS-active medications and fall risk due to more distant use being less strongly associated with risk as compared to new use. While depression was not measured, we assessed perceived health which is an indication of poor mental health after controlling for objective health status and physical function [45]. While we controlled the analyses for the clinic site and frequency leaving the neighborhood, a possible limitation of this study is that we did not assess indoor home hazards or variation in neighborhoods with respect to snow removal, quality of sidewalks, and cleanliness.

In a large sample of over 8,300 Caucasian communitydwelling women involving the most comprehensive study of risk factors for falls, we identified five potentially modifiable physical risk factors for falls that each contribute to $5 \%$ or more of falls in the population. Lifestyles had an independent association with falls, which suggests that environmental and behavioral risk factors are important causes of falls in older women. Thus, these findings underscore the importance of multidimensional fall interventions which include lifestylerelated environmental and behavioral risk factors to more effectively reduce the burden of falls in older women. Future research should identify mechanisms through which lifestyle factors and shorter body height may influence fall risk in older women. Additional research is needed to examine the relative importance of physical and lifestyle factors in men and in women of other ethnic backgrounds and separately in older individuals at high and low risk for falls where the relevance of different risk factor domains may vary dramatically.

\section{Conflicts of interest None.}

Funding This study received funding through these grant numbers: AG05407, AR35582, AG027576-22, AG05394, AG005394-22A1, AR35584, AR35583, AG027574-22A1, and P30 AG024827.

Open Access This article is distributed under the terms of the Creative Commons Attribution Noncommercial License which permits any noncommercial use, distribution, and reproduction in any medium, provided the original author(s) and source are credited.

\section{References}

1. O’Loughlin JL, Robitaille Y, Boivin JF, Suissa S (1993) Incidence of and risk factors for falls and injurious falls among the community-dwelling elderly. Am J Epidemiol 137:342-354

2. CDC (2008) Self-reported falls and fall-related injuries among persons aged \&gt; or $=65$ years-United States, 2006. MMWR Morb Mortal Wkly Rep 57:225-229 
3. Centers for Disease Control and Prevention NCfIPaC (2006 [cited 2007 Jan 15]) Web-based Injury statistics Query and Reporting System (WISQARS) [online]. In

4. Kannus P, Parkkari J, Koskinen S, Niemi S, Palvanen M, Jarvinen M, Vuori I (1999) Fall-induced injuries and deaths among older adults. JAMA 281:1895-1899

5. Stevens JA, Corso PS, Finkelstein EA, Miller TR (2006) The costs of fatal and non-fatal falls among older adults. Inj Prev 12:290-295

6. Campbell AJ, Borrie MJ, Spears GF (1989) Risk factors for falls in a community-based prospective study of people 70 years and older. J Gerontol 44:M112-M117

7. Hanlon JT, Landerman LR, Fillenbaum GG, Studenski S (2002) Falls in African American and white community-dwelling elderly residents. J Gerontol A Biol Sci Med Sci 57:M473-M478

8. Leipzig RM, Cumming RG, Tinetti ME (1999) Drugs and falls in older people: a systematic review and meta-analysis: I. Psychotropic drugs. J Am Geriatr Soc 47:30-39

9. Nevitt MC, Cummings SR, Kidd S, Black D (1989) Risk factors for recurrent nonsyncopal falls. A prospective study. JAMA 261:2663-2668

10. Tinetti ME, Speechley M, Ginter SF (1988) Risk factors for falls among elderly persons living in the community. N Engl J Med 319:1701-1707

11. Studenski S, Duncan PW, Chandler J, Samsa G, Prescott B, Hogue C, Bearon LB (1994) Predicting falls: the role of mobility and nonphysical factors. J Am Geriatr Soc 42:297-302

12. Rubenstein LZ, Josephson KR (2002) The epidemiology of falls and syncope. Clin Geriatr Med 18:141-158

13. Dunn JE, Rudberg MA, Furner SE, Cassel CK (1992) Mortality, disability, and falls in older persons: the role of underlying disease and disability. Am J Public Health 82:395-400

14. Schwartz AV, Nevitt MC, Brown BW Jr, Kelsey JL (2005) Increased falling as a risk factor for fracture among older women: the study of osteoporotic fractures. Am J Epidemiol 161:180-185

15. Lamb SE, Jorstad-Stein EC, Hauer K, Becker C (2005) Development of a common outcome data set for fall injury prevention trials: the Prevention of Falls Network Europe consensus. J Am Geriatr Soc 53:1618-1622

16. Bailey IL, Lovie JE (1976) New design principles for visual acuity letter charts. Am J Optom Physiol Opt 53:740-745

17. Ginsburg AP (1984) A new contrast sensitivity vision test chart. Am J Optom Physiol Opt 61:403-407

18. Gibson JJ (1950) The perception of visual surfaces. Am J Psychol 63:367-384

19. Folstein MF, Robins LN, Helzer JE (1983) The Mini-Mental State Examination. Arch Gen Psychiatry 40:812

20. Pincus T, Summey JA, Soraci SA Jr, Wallston KA, Hummon NP (1983) Assessment of patient satisfaction in activities of daily living using a modified Stanford Health Assessment Questionnaire. Arthritis Rheum 26:1346-1353

21. May D, Nayak US, Isaacs B (1985) The life-space diary: a measure of mobility in old people at home. Int Rehabil Med 7:182-186

22. Paffenbarger RS Jr, Hyde RT, Wing AL, Hsieh CC (1986) Physical activity, all-cause mortality, and longevity of college alumni. N Engl J Med 314:605-613

23. Liang KY, Zeger SL (1986) Longitudinal data analysis using generalized linear models. Biometrika 73:13-22

24. Gelman A (2008) Scaling regression inputs by dividing by two standard deviations. Stat Med 27:2865-2873

25. Coleman AL, Stone K, Ewing SK, Nevitt M, Cummings S, Cauley JA, Ensrud KE, Harris EL, Hochberg MC, Mangione CM (2004) Higher risk of multiple falls among elderly women who lose visual acuity. Ophthalmology 111:857-862

26. Graafmans WC, Ooms ME, Hofstee HM, Bezemer PD, Bouter LM, Lips P (1996) Falls in the elderly: a prospective study of risk factors and risk profiles. Am J Epidemiol 143:1129-1136
27. Pluijm SM, Smit JH, Tromp EA, Stel VS, Deeg DJ, Bouter LM, Lips P (2006) A risk profile for identifying community-dwelling elderly with a high risk of recurrent falling: results of a 3-year prospective study. Osteoporos Int 17:417-425

28. Ensrud KE, Blackwell TL, Mangione CM, Bowman PJ, Whooley MA, Bauer DC, Schwartz AV, Hanlon JT, Nevitt MC (2002) Central nervous system-active medications and risk for falls in older women. J Am Geriatr Soc 50:1629-1637

29. Chan BK, Marshall LM, Winters KM, Faulkner KA, Schwartz AV, Orwoll ES (2007) Incident fall risk and physical activity and physical performance among older men: the Osteoporotic Fractures in Men Study. Am J Epidemiol 165:696-703

30. Binda SM, Culham EG, Brouwer B (2003) Balance, muscle strength, and fear of falling in older adults. Exp Aging Res 29:205-219

31. Allum JH, Carpenter MG, Honegger F, Adkin AL, Bloem BR (2002) Age-dependent variations in the directional sensitivity of balance corrections and compensatory arm movements in man. J Physiol 542:643-663

32. Howland J, Lachman ME, Peterson EW, Cote J, Kasten L, Jette A (1998) Covariates of fear of falling and associated activity curtailment. Gerontologist 38:549-555

33. Faulkner KA, Cauley JA, Zmuda JM, Griffin JM, Nevitt MC (2003) Is social integration associated with the risk of falling in older community-dwelling women? J Gerontol A Biol Sci Med Sci 58:M954-M959

34. Pavol MJ, Owings TM, Foley KT, Grabiner MD (2001) Mechanisms leading to a fall from an induced trip in healthy older adults. J Gerontol A Biol Sci Med Sci 56:M428-M437

35. Niino N, Tsuzuku S, Ando F, Shimokata H (2000) Frequencies and circumstances of falls in the National Institute for Longevity Sciences, Longitudinal Study of Aging (NILS-LSA). J Epidemiol 10:S90-S94

36. Gill TM, Robison JT, Williams CS, Tinetti ME (1999) Mismatches between the home environment and physical capabilities among community-living older persons. J Am Geriatr Soc 47:88-92

37. Huang TT (2005) Home environmental hazards among communitydwelling elderly persons in Taiwan. J Nurs Res 13:49-57

38. Li F, Fisher KJ, Harmer P, McAuley E (2005) Falls self-efficacy as a mediator of fear of falling in an exercise intervention for older adults. J Gerontol B Psychol Sci Soc Sci 60:P34-P40

39. Voukelatos A, Cumming RG, Lord SR, Rissel C (2007) A randomized, controlled trial of tai chi for the prevention of falls: the Central Sydney tai chi trial. J Am Geriatr Soc 55:1185-1191

40. Wagner EH, LaCroix AZ, Grothaus L, Leveille SG, Hecht JA, Artz K, Odle K, Buchner DM (1994) Preventing disability and falls in older adults: a population-based randomized trial. Am J Public Health 84:1800-1806

41. Campbell AJ, Robertson MC, Gardner MM, Norton RN, Buchner DM (1999) Psychotropic medication withdrawal and a homebased exercise program to prevent falls: a randomized, controlled trial. J Am Geriatr Soc 47:850-853

42. Cumming RG, Ivers R, Clemson L, Cullen J, Hayes MF, Tanzer M, Mitchell P (2007) Improving vision to prevent falls in frail older people: a randomized trial. J Am Geriatr Soc 55:175-181

43. Society AG, Society BG, AAoOSPoF P (2001) Guideline for the Prevention of Falls in Older People. Journal of the American Geriatrics Society 49:664-672

44. Gates S, Fisher JD, Cooke MW, Carter YH, Lamb SE (2008) Multifactorial assessment and targeted intervention for preventing falls and injuries among older people in community and emergency care settings: systematic review and meta-analysis. BMJ 336:130-133

45. Ruo B, Baker DW, Thompson JA, Murray PK, Huber GM, Sudano JJ Jr (2008) Patients with worse mental health report more physical limitations after adjustment for physical performance. Psychosom Med 70:417-421 